\title{
Grade outcomes or studies: how to use grade approach correctly
}

\author{
Frans-Jasper Wijdicks
}

Received: 20 December 2012 / Accepted: 20 December 2012 /Published online: 12 January 2013

(C) European Union 2013

\section{Dear Editor,}

We would like to thank the authors of the letter to the editor by Mao et al. for their critical look at our article [1]. We would like to address their points.

The GRADE approach was used to add to our identification of the quality of evidence of studies [2]. By using the GRADE in combination with the QAT the authors drew conclusions regarding quality of evidence [3]. We acknowledge the rules and guidelines of the GRADE approach but the authors wanted to use two quality tools in making a good identification of quality of evidence.

Regarding the second point, we cross-referenced the study by Ferran et al. with the five factors that may decrease the quality of evidence of this study, but the study of Ferran et al. was not compromised by one of these limitations [4]. The study by Bohme et al. was a prospective observational study which automatically was graded as low evidence, and did not yield a large enough effect to be considered for an upgrade on the GRADE approach [5]. The studies by Liu et al. and Thyagarajan et al. were retrospective observational case series and were downgraded from low to very low due to the limitations in the design $[6,7]$.

Our conclusions regarding the level of evidence for the studies included is not based solely on the GRADE approach but is a combination of the GRADE and the QAT $[2,3]$. When combining both quality scores we regard the study of Ferran et al. as high quality of evidence [4]. The authors do not necessarily apply the definition of high quality evidence of the GRADE on this study. The main goal of this study was to identify what evidence was available for a superior operative technique regarding dislocated midshaft clavicle fractures.

Sincerely,

F.J.G. Wijdicks

\section{References}

1. Houwert RM, Wijdicks FJ, Steins Bisschop C, Verleisdonk EJ, Kruyt M (2012) Plate fixation versus intramedullary fixation for displaced mid-shaft clavicle fractures: a systematic review. Int Orthop 36:579-585. doi:10.1007/s00264-0111422-4

2. The Cochrane Handbook (2011) Webpage The Cochrane Handbook for Systematic Reviews of Interventions, version 5.1.0. http:// handbook.cochrane.org/

3. CEBM (2012) Webpage. Centre for Evidence-based Medicine, Oxford, UK.http://www.cebm.net. Accessed 03 January 2013

4. Ferran NA, Hodgson P, Vannet N, Williams R, Evans RO (2010) Locked intramedullary fixation vs plating for displaced and shortened mid-shaft clavicle fractures: a randomized clinical trial. J Shoulder Elbow Surg 19:783-789

5. Böhme J, Bonk A, Bacher GO, Wilharm A, Hoffmann R, Josten C (2010) Current treatment concepts for mid-shaft fractures of the clavicle - results of a prospective multicentre study. Z Orthop Unfall 149(1):68-76

6. Liu HH, Chang CH, Chia WT, Chen $\mathrm{CH}$, Tarng YW, Wong CY (2010) Comparison of plates versus intramedullary nails for fixation of displaced midshaft clavicular fractures. J Trauma 69(6):E82-E87

7. Thyagarajan DS, Day M, Dent C, Williams R, Evans R (2009) Treatment of mid-shaft clavicle fractures: a comparative study. Int J Shoulder Surg 3(2):23-27
F.-J. Wijdicks $(\bowtie)$

Diakonessenhuis Utrecht Surgery, Utrecht, Netherlands

e-mail: fjgwijdicks@gmail.com 